\title{
EXTRATO METANÓLICO DA AMÊNDOA DA SEMENTE DE NIM E A MORTALIDADE DE OVOS E LAGARTAS DA TRAÇA-DO-TOMATEIRO
}

\author{
Roseane Cristina Prédes Trindade ${ }^{1,4 *}$; Irene Maria Ramos Marques²; Haroudo Satiro Xavier; \\ José Vargas de Oliveira ${ }^{1}$ \\ ${ }^{1}$ Depto. de Fitossanidade - UFRPE, Rua Dom Manoel de Medeiros, s/n - Dois Irmãos - CEP: 52171-900 - Recife, PE. \\ ${ }^{2}$ Depto. de Zoologia - UFPE, Av. Prof. Moraes Rego, 1235 - Cidade Universitária - CEP: 50670-420 - Recife, PE. \\ ${ }^{3}$ Depto. de Ciências Farmacêuticas - UFPE. \\ ${ }^{4}$ Bolsista CAPES. \\ *Autor correspondente <trindade@nelore.npde.ufrpe.br>
}

RESUMO: Estudou-se o efeito tóxico do extrato metanólico da amêndoa da semente de nim, obtido pelo aparelho de Soxhlet, na mortalidade de ovos e lagartas de Tuta absoluta (Meyrick) (Lepidoptera: Gelechiidae). Para constatação do efeito ovicida, ovos com 24 horas da oviposição foram contados e pulverizados com extrato nas concentrações $1000 ; 500 ; 250 ; 125$ e $62,5 \mathrm{mg} \mathrm{L}^{-1}$. As testemunhas foram pulverizadas com água e metanol. O experimento foi mantido, em laboratório, a $25 \pm 2^{\circ} \mathrm{C}$; UR de $50 \pm 10 \%$ e fotofase de $12 \mathrm{~h}$. O período de incubação, para todos os tratamentos inclusive as testemunhas, foi em média de quatro dias, sendo que o extrato não afetou a viabilidade dos ovos, embora os valores tenham variado de $51,7 \%$ a $80,6 \%$. Lagartas recém-eclodidas foram colocadas em tubos contendo um folíolo de tomateiro, previamente imerso em extrato, nas concentrações de 2000; 4000; 6000 e $8000 \mathrm{mg} \mathrm{L}^{-1}$ e acondicionados na câmara climatizada à $27 \pm 1^{\circ} \mathrm{C}$; UR: $65 \pm 10 \%$ e fotofase: $12 \mathrm{~h}$. Aos quatro dias, causaram mortalidade de $82,68,94,7$ e $100 \%$, respectivamente, sendo que, ao sexto dia, todas as concentrações tinham causado $100 \%$ de mortalidade da fase larval. As testemunhas tratadas com água e com metanol apresentaram mortalidade de $4 \%$ e $8 \%$, respectivamente. Palavras-chave: Tuta absoluta, planta inseticida, inseticida natural, nim, tomate

\section{NEEM SEED KERNEL EXTRACT AND THE TOMATO LEAFMINER EGG AND LARVAE MORTALITY}

\begin{abstract}
A methanolic extract from neem seed kernels, obtained using the Soxhlet apparatus was used to study the mortality of eggs and larvae of Tuta absoluta (Lepidoptera: Gelechiidae) and to evaluate of the ovicidal effect. Eggs 24 hours after oviposition were counted and sprayed with the extract at the concentrations of 1000 , $500,250,125$ and $62.5 \mathrm{mg} \mathrm{L}^{-1}$. Controls were sprayed with water and methanol. The experiment was conducted in laboratory conditions at $25 \pm 2{ }^{\circ} \mathrm{C}$; UR $50 \pm 10 \%$ and $12 \mathrm{~h}$ of photophase. Incubation period for all treatments, including controls, was four days on the average. The extract did not affect the viability of eggs, although the values varied between of $51.7 \%$ the $80.6 \%$. Larvae recently hatched from eggs were placed in glass tubes containing a tomato leaflet previously immersed for five seconds into the extract, at concentrations of 2000 , 4000,6000 and $8000 \mathrm{mg} \mathrm{L}^{-1}$ and conditioned on $\mathrm{BOD}$ at $27 \pm 1^{\circ} \mathrm{C} ; 65 \pm 10 \% \mathrm{RH}$ and 12 hours of light. By the fourth day after treatment the extract caused mortalities of $82,68,94.7$ and $100 \%$, respectively. By the sixth day, all concentrations caused $100 \%$ mortality of the larvae. The controls with water and methanol presented mortalities of 4 and $8 \%$, respectively.
\end{abstract}

Key words: Tuta absoluta, insecticidal plants, natural insecticide, neem, tomato

\section{INTRODUÇÃO}

A traça-do-tomateiro, Tuta absoluta (Meyrick, 1917) (Lepidoptera: Gelechiidae), é considerada uma das pragas mais importantes da cultura do tomateiro no Brasil, causando danos às gemas, brotos terminais, flores, folhas, inserção dos ramos e frutos (Souza et al., 1983; Haji, 1984; Haji et al., 1989; França \& Castelo Branco, 1992). É uma espécie difícil de ser controlada, pelo fato de ocorrer durante todo o ciclo da cultura (Haji, 1982; Souza \& Reis, 1986; Villas Bôas \& França, 1996), ter seu elevado potencial biótico, com hábito de construir minas nas folhas durante a fase larval e da capacidade de desenvolver resistência, pelo uso de inseticidas (Imenes et al., 1990).
O uso freqüente e indiscriminado de produtos químicos, muitas vezes tem acarretado a presença de altos níveis de resíduos tóxicos nos alimentos, desequilíbrio biológico, contaminações ambientais, intoxicações de pessoas e animais, ressurgência de pragas, surtos de pragas secundárias e o aparecimento de linhagens de insetos resistentes (Saxena, 1989). Uma alternativa para atenuar esses problemas é a utilização de aleloquímicos extraídos de plantas. Dentre as espécies botânicas mais utilizadas, atualmente, como fonte de aleloquímicos, encontram-se as Famílias Meliaceae, Rutaceae, Asteraceae, Annonaceae, Lamiaceae e Canellaceae (Jacobson, 1989). 
Atualmente, dentre as espécies vegetais com atividade inseticida, a mais estudada é o nim, Azadirachta indica A. Juss., Meliaceae sub-tropical, também conhecida como "Margosa tree" ou "Indian Lilac", nativa das regiões áridas da Ásia e África, e que se encontra distribuída também na Austrália e América (Ahmed \& Grainge, 1986; Schmutterer, 1988, 1990; Saxena, 1989; Mordue \& Blackwell, 1993). A azadiractina, um tetranortriterpenóide isolado da semente de nim, constitui o mais importante princípio ativo do ponto de vista entomológico (Jacobson, 1989). Esta substância tem efeito repelente, intoxicante, regula o crescimento e a metamorfose dos insetos, causa deterrência alimentar, afeta a biologia, a oviposição e a viabilidade dos ovos (Schmutterer, 1988; Jacobson, 1989; Saxena, 1989; Schmutterer, 1990; Mordue \& Blackwell, 1993; Neves \& Nogueira, 1996).

Os compostos bioativos de nim são utilizados na forma de pós, extratos aquosos e/ou orgânicos (metanólico, etanólico, acetônico, clorofórmico, hexânico), óleos e pasta, além de frações parcialmente purificadas e formulações ricas em azadiractina (Saxena, 1989). O local de origem, idade das sementes e solvente utilizado na extração, podem ocasionar variações nos teores do princípio ativo e na sua atividade biológica (Schmutterer, 1987).

Existem poucos resultados de pesquisas utilizando extratos de plantas para o controle da traça-do-tomateiro. Ferracini et al. (1990) realizaram ensaios in vitro com extratos aquosos e orgânicos de Simaba cedron, Simaruba amara, Quassia sp., Melia azedarach e Chenopodium ambrosioides e constataram que, o Simaruba (raiz/ metanólico), Simaba (folhas/metanólico) e Melia (fruto/ acetônico e metanólico) provocaram mortalidade em torno de $80 \%$, enquanto que Quasia (folhas/etanólico) provocou $100 \%$ de mortalidade. Ferracini et al. (1993) utilizaram extratos aquosos e acetônicos de $M$. azedarach pulverizado sobre tomateiros envasados, observando resultados satisfatórios com $52 \%$ e $62 \%$ de mortalidade larval para o extrato aquoso e acetônico, respectivamente. Thomazini (1999) avaliou, em laboratório, o efeito de extratos aquosos de folhas e ramos de Trichilia pallida, a 0,$1 ; 1,0$ e 5,0\%, sobre o desenvolvimento e oviposição da traça-do-tomateiro e verificou que os extratos de folhas e de ramos prejudicaram o desenvolvimento afetando, principalmente, a fase larval. O extrato de folhas a $5 \%$ não apresentou efeito ovicida mas, dependendo da densidade populacional do inseto, o substrato tratado tornou-se menos preferido para oviposição.

Existem poucas informações sobre a ação ovicida dos compostos bioativos de nim em insetos. Dados avaliados mostram que aplicações de altas concentrações de extratos de plantas resultam em poucos ou em nenhum efeito ovicida (Schmutterer, 1987). Produtos de nim geralmente não causam efeito ovicida, mas seu efeito residual é, muitas vezes, suficientemente longo para impedir a primeira ecdise de larvas eclodidas de ovos tratados (Schmutterer, 1988).
Considerando a carência de pesquisas com plantas inseticidas visando controlar a traça-do-tomateiro, justifica-se, deste modo, o desenvolvimento de estudos com plantas promissoras. Assim, o objetivo desse trabalho foi avaliar, em laboratório, o efeito do extrato metanólico da amêndoa da semente de nim sobre a mortalidade de ovos e lagartas de $T$. absoluta.

\section{MATERIAL E MÉTODOS}

Os experimentos foram desenvolvidos no Laboratório de Biologia de Insetos, Área de Fitossanidade, Departamento de Agronomia, da Universidade Federal Rural de Pernambuco (UFRPE). O experimento constou das seguintes etapas:

Condução da cultura: Plantas de tomateiro, Lycopersicon esculentum cv. Santa Clara, foram cultivadas em casa-devegetação, mediante formação de sementeiras em bandejas de isopor preenchidas com substrato. Após 15 dias da semeadura, as mudas foram transplantadas para vasos de $25 \mathrm{~cm}$ de diâmetro e $20 \mathrm{~cm}$ de altura, contendo solo esterilizado e húmus (4:1). Para o controle eventual do microácaro Aculops lycopersici, utilizou-se o acaricida abamectina (Vertimec $18 \mathrm{CE}$ ) na dosagem de $1 \mathrm{~mL} \mathrm{~L}^{-1}$ de água, sendo obedecida um intervalo de segurança de 15 dias, para a utilização das folhas do tomateiro pelas lagartas.

Criação da traça-do-tomateiro: A criação, segundo metodologia descrita por Pratissoli (1995), foi conduzida em laboratório, a $29 \pm 1^{\circ} \mathrm{C}, 55 \pm 5 \%$ de UR e fotoperíodo de $12 \mathrm{~h}$, a partir de lagartas e pupas coletadas em campos de tomateiro comercial Santa Clara, no município de Camocin de São Félix, PE. Os adultos foram mantidos em gaiola de madeira e tela de náilon de $2 \mathrm{~mm}(1,0 \times 1,0 \times$ $0,50 \mathrm{~m}$ ), sendo alimentados com solução açucarada a $10 \%$, fornecida em algodão acondicionado em pequenos tubos de vidro, distribuídos na base da gaiola. Para obtenção das posturas foram colocados no interior da gaiola pecíolos de tomateiro imersos em vidros com água. Após a oviposição, recipientes de vidros contendo folhas com as posturas, foram colocados sobre bandejas com areia esterilizada para servir como substrato para a pupação. Periodicamente, as folhas danificadas pelas lagartas eram substituídas por outras folhas novas. As folhas secas que continham as pupas e aquelas coletadas na areia, eram transferidas para a gaiola de madeira.

Preparo dos extratos: Sementes de nim foram coletadas na sede da EMBRAPA - Semi-Árido, no município de Petrolina, PE. Utilizaram-se nos experimentos, extratos orgânicos, preparados no Laboratório de Farmacognosia, do Departamento de Ciências Farmacêuticas, da Universidade Federal de Pernambuco (UFPE).

As sementes inteiras foram colocadas em água e mantidas em repouso por um período de $48 \mathrm{~h}$, sendo 
posteriormente descascadas, colocadas em estufa à $40^{\circ} \mathrm{C}$ para secagem total da amêndoa e, em seguida, trituradas em moinho elétrico obtendo-se um pó fino. Este foi acondicionado em recipiente hermeticamente fechado até o preparo do extrato, para o qual utilizou-se o aparelho soxhlet, empregando-se os solventes acetato de etila e metanol, segundo adaptação da metodologia descrita por Boff \& Almeida (1996). Na extração, uma amostra de 100 $\mathrm{g}$ do pó foi colocada no extrator de soxhlet, junto com 1000 $\mathrm{mL}$ de solvente, permanecendo cada amostra sob refluxo durante $24 \mathrm{~h}$. O extrato filtrado foi concentrado em rotavapor a $40^{\circ} \mathrm{C}$, à pressão reduzida. O resíduo de 32,63 g obtido na extração foi dissolvido em metanol, sendo o volume ajustado a uma dada concentração, colocado em frasco escuro e armazenado em geladeira $a \pm 5^{\circ} \mathrm{C}$.

Efeito dos extratos na mortalidade de ovos: $O$ extrato foi diluído em metanol para obtenção das concentrações 1000; 500; 250; 125 e 62,5 $\mathrm{mg} \mathrm{L}^{-1}$. Em seguida, foram colocados na gaiola de criação da traça-do-tomateiro, recipientes de vidro contendo um ramo originário do terço apical de plantas da cultivar Santa Clara, com cinco folíolos, tendo seus pecíolos imersos em água para manutenção da turgescência, os quais serviram de substrato para postura. Após $24 \mathrm{~h}$ da oviposição, os folíolos foram pulverizados com mini pulverizador manual, com um volume de $5 \mathrm{~mL}$ de cada concentração. Nas testemunhas, os folíolos foram pulverizados com $5 \mathrm{~mL}$ de água destilada e metanol. Os folíolos pulverizados permaneceram ao ar livre, por cerca de $12 \mathrm{~h}$, até a evaporação do metanol ou da água. Diariamente, era observado o número de lagartas eclodidas em cada folíolo, quando se determinou o período de incubação e a viabilidade dos ovos. O experimento foi mantido, em laboratório, a $25 \pm 2^{\circ} \mathrm{C}$; UR de $50 \pm 10 \%$ e fotofase de 12 h. O delineamento experimental utilizado foi inteiramente casualizado, com sete tratamentos e cinco repetições. Todos os parâmetros foram submetidos a análise de variância, sendo a comparação entre médias dos tratamentos feita pelo teste de Tukey $(P \leq 0,05)$, através do programa computacional SANEST (Versão 3.0).

Efeito dos extratos na mortalidade de lagartas: $O$ extrato foi diluído em metanol para obtenção das concentrações 2000, 4000, 6000 e $8000 \mathrm{mg} \mathrm{L}^{-1}$. Em seguida, procedeu-se a imersão dos folíolos de tomateiro em cada concentração por cerca de cinco segundos, conforme os procedimentos recomendados pelo Grupo Internacional das Associações Nacionais de Fabricantes de Produtos Agroquímicos (GIFAP) para lagartas que se alimentam de folhas de hortaliças (Guedes et al., 1995). As testemunhas, foram constituídas por folíolos imersos em água destilada e em metanol. Após a imersão, os folíolos foram preservados sobre papel toalha, por cerca de $12 \mathrm{~h}$, até a evaporação do metanol e da água. Lagartas da traça-do-tomateiro recém-eclodidas foram inoculadas em cada folíolo contido em tubos de vidro, com o pecíolo envolto em algodão umedecido com água destilada, para manutenção da turgescência, fechados com filme plástico transparente PVC (Magipack ${ }^{\circledR}$ ) e acondicionados em câmara climatizada a $27 \pm 1^{\circ} \mathrm{C}$; UR: $65 \pm 10 \%$ e fotofase: 12 h. A avaliação da mortalidade larval foi realizada diariamente até o sexto dia. O delineamento experimental utilizado foi inteiramente casualizado com seis tratamentos e cinco repetições. Todos os parâmetros foram submetidos a análise de variância, sendo a comparação entre médias dos tratamentos feita pelo teste de Tukey $(P \leq 0,05)$, onde os dados de mortalidade diária acumulada no primeiro e segundo dia foram transformados em log $(x+0,5)$, através do programa computacional SANEST (Versão 3.0).

\section{RESULTADOS E DISCUSSÃO}

\section{Efeito dos extratos na mortalidade de ovos}

Não foi verificado efeito tóxico do extrato metanólico da amêndoa da semente de nim, na viabilidade dos ovos da traça-do-tomateiro (Figura 1).

O período de incubação dos ovos, para todos os tratamentos, foi em média de 4,32 $\pm 0,02$ dias, não havendo diferença estatística significativa entre eles; os ovos apresentaram coloração branco-brilhante ou amareloclaro inicialmente, e marrom ou avermelhado, próximo à eclosão, em todos os tratamentos, semelhantemente ao encontrado por Coelho \& França (1987) e Haji et al. (1988), quando estudaram a biologia da traça-do-tomateiro, em laboratório.

Outros trabalhos realizados mostram que aplicações de altas concentrações de extratos de plantas, resultam em pequenos efeitos ou em nenhum efeito ovicida (Schmutterer, 1987). Por exemplo, folhas de algodoeiro, Gossypium hirsutum, contendo posturas de Bemisia tabaci, foram pulverizadas com 0,0;0,2 e $2 \%$ do extrato aquoso da semente de nim. A concentração $0,2 \%$ não reduziu significativamente a viabilidade dos ovos, em 6 dias, entretanto, com 2,0\% a viabilidade foi reduzida para 29\% (Coudriet et al., 1985). Souza \& Vendramin (1998) avaliaram a ação ovicida dos extratos aquosos de duas meliáceas, sobre ovos de Bemisia argentifolii, em

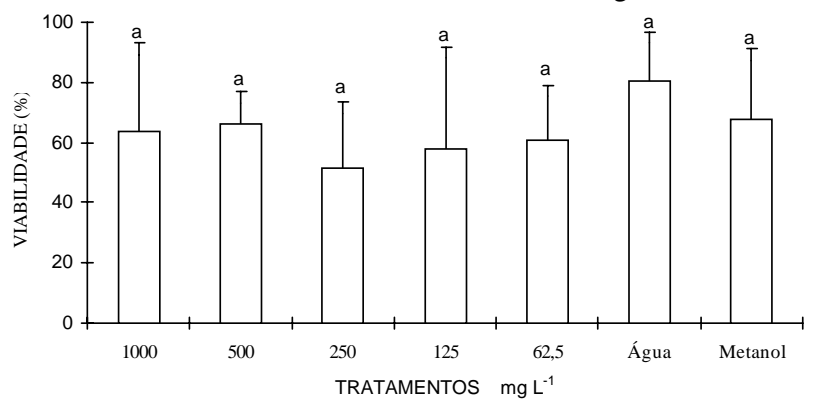

Figura 1 - Médias \pm (IC) da viabilidade de ovos de Tuta absoluta tratados com extratos metanólicos da amêndoa da semente de Azadirachta indica. Temperatura: $25 \pm 2{ }^{\circ} \mathrm{C}$; UR: $50 \pm 10 \%$; fotofase: $12 \mathrm{~h}$. Médias com mesma letra não diferem pelo teste de Tukey $(P \leq 0,5)$ 
tomateiro. Os dois extratos apresentaram ação ovicida, sendo que $M$. azedarach foi mais eficaz do que T. pallida. No extrato de $M$. azedarach foi verificado que algumas ninfas morreram sem ter completado a eclosão.

Beament \& Lal (1957) constataram, em ovos de Pieris brassicae, a existência de uma membrana e estudaram seu papel na penetração de ovicidas. Foi constatando que ocorre a substituição da membrana vitelínea, poucas horas após a oviposição, a qual é dissolvida, pouco antes da eclosão das lagartas. Smith \& Salkeld (1966) constataram em ovos de lepidópteros a ocorrência de uma camada lipídica ou cerosa na parte interna do córion, envolvendo a membrana epembriônica, a qual provavelmente é um fator responsável pela retenção dos ovicidas, fazendo com que ovos de muitos lepidópteros não apresentem sensibilidade aos produtos com ação ovicida.

A existência da membrana epembriônica nos ovos seria a responsável pela dificuldade de penetração de compostos lipossolúveis, até o embrião. Desta forma, os resultados sugerem, que ovos da traça-do-tomateiro possam apresentar essa membrana e a camada cerosa ou lipídica, constituindo, portanto, barreiras à penetração do princípio ativo do extrato metanólico da amêndoa de nim.

No entanto, alguns trabalhos apresentam resultados positivos do efeito ovicida de aleloquímicos contra lepidópteros. Boff \& Almeida (1996) avaliaram o efeito tóxico dos extratos metanólicos e/ou acetônicos de pimenta-do-reino, Piper nigrum, obtidos pelos métodos utilizando o aparelho de Soxhlet e macerado, sobre ovos de diferentes idades de Sitrotoga cerealella. Os resultados demonstraram que os quatro extratos apresentaram efeito tóxico crescente em função da concentração, para todas as idades de ovos e os dois métodos de extração não interferiram nos resultados. Verkerk \& Wright (1993) relataram que azadiractina possui efeito ovicida contra a traça-das-crucíferas, Plutella xylostella, nas doses de 10

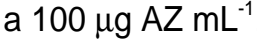

No caso de coleópteros da família Bruchidae, o efeito ovicida já é bem esclarecido, devido a estudos das estruturas dos ovos desses insetos. Desta forma, Credland (1992) estudou a estrutura do ovo de quatro espécies de Callosobruchus e Zabrotes subfasciatus, a fim de explicar o eficiente efeito ovicida de óleos. Verificou-se que ovos de Callosobruchus têm um espaço largo incluso entre o ovo e o tegumento da semente. Este espaço é conectado com o exterior, através de um pequeno funil no final da parte posterior do ovo, que supostamente é a razão para um bom efeito do ovicida e, provavelmente, também larvicida. Desta forma, essa diferença da estrutura do ovo entre as espécies pode explicar o tradicional uso de óleos no controle de Callosobruchus, quando comparado com outras espécies.

\section{Efeito dos extratos na mortalidade de lagartas}

No primeiro e segundo dias, após a aplicação dos extratos já foi verificado um percentual elevado de mortalidade das lagartas em todos os tratamentos com extrato. A inexistência de diferença estatística significativa entre a mortalidade acumulada das testemunhas água e metanol, constatada apenas no primeiro dia, de $4 \%$ e $8 \%$, respectivamente, e permanecendo constante até o último dia da avaliação, indica que o metanol utilizado para diluir o extrato não afetou a mortalidade larval (TABELA 1).

No terceiro dia, na maior concentração já havia sido constatada mortalidade de $90,7 \%$ das lagartas, havendo diferença significativa das concentrações $2000 \mathrm{e}$ $4000 \mathrm{mg} \mathrm{L}^{-1}$, com mortalidade acumulada de $46,0 \% \mathrm{e}$

TABELA 1 - Médias \pm (Erro Padrão) da mortalidade diária acumulada (\%) de lagartas de Tuta absoluta, alimentadas com folhas de tomateiro tratadas com diferentes concentrações do extrato metanólico da amêndoa da semente de Azadirachta indica. Temperatura: $27 \pm 1^{\circ} \mathrm{C}$; UR: $65 \pm 10 \%$; Fotofase: $12 \mathrm{~h}$.

\begin{tabular}{|c|c|c|c|c|c|c|c|}
\hline \multicolumn{8}{|c|}{ Mortalidade diária acumulada $(\%)^{1}$} \\
\hline \multirow[b]{2}{*}{ Tratamentos } & \multirow[b]{2}{*}{$\begin{array}{c}\mathrm{N}^{\circ} \text { de } \\
\text { lagartas }\end{array}$} & \multicolumn{6}{|c|}{ Dias após o tratamento } \\
\hline & & 1 & 2 & 3 & 4 & 5 & 6 \\
\hline $\begin{array}{l}\text { Extrato } \\
2000 \mathrm{mg} \mathrm{L}^{-1}\end{array}$ & 50 & $34,0 \pm 6,78 a$ & $40,0 \pm 8,94 a$ & $46,0 \pm 9,27 b$ & $82,0 \pm 5,83 a b$ & $88,0 \pm 3,74 a b$ & $100,0 \pm 0,00 a$ \\
\hline $\begin{array}{l}\text { Extrato } \\
4000 \mathrm{mg} \mathrm{L}^{-1}\end{array}$ & 50 & $32,0 \pm 5,83 a$ & $38,0 \pm 4,90 \mathrm{a}$ & $42,0 \pm 3,74 b$ & $68,0 \pm 6,63 b$ & $80,0 \pm 4,47 \mathrm{~b}$ & $100,0 \pm 0,00 a$ \\
\hline $\begin{array}{l}\text { Extrato } \\
6000 \mathrm{mg} \mathrm{L}^{-1}\end{array}$ & 37 & $45,9 \pm 12,97 a$ & $45,9 \pm 12,97 a$ & $63,3 \pm 13,10 a b$ & $94,6 \pm 3,43 a$ & $96,7 \pm 3,33 \mathrm{a}$ & $100,0 \pm 0,00 a$ \\
\hline $\begin{array}{l}\text { Extrato } \\
8000 \mathrm{mg} \mathrm{L}^{-1}\end{array}$ & 75 & $21,3 \pm 3,83 a$ & $60,0 \pm 9,89 a$ & $90,7 \pm 2,67 a$ & $100,0 \pm 0,00 a$ & $100,0 \pm 0,00 a$ & $100,0 \pm 0,00 a$ \\
\hline $\begin{array}{l}\text { Testemunha } \\
\text { Água }\end{array}$ & 50 & $4,0 \pm 2,45 b$ & $4,0 \pm 2,45 b$ & $4,0 \pm 2,45 c$ & $4,0 \pm 2,45 c$ & $4,0 \pm 2,45 c$ & $4,0 \pm 2,45 b$ \\
\hline $\begin{array}{l}\text { Te stemunha } \\
\text { Metanol }\end{array}$ & 50 & $8,0 \pm 5,83 b$ & $8,0 \pm 5,83 b$ & $8,0 \pm 5,83 c$ & $8,0 \pm 5,83 c$ & $8,0 \pm 5,83 c$ & $8,0 \pm 5,83 b$ \\
\hline CV $(\%)$ & & 30,90 & 30,36 & 27,43 & 17,49 & 13,41 & 8,40 \\
\hline
\end{tabular}

${ }^{1}$ Médias seguidas da mesma letra, nas colunas, não diferem pelo teste de Tukey $(P \leq 0,5)$ 
$42,0 \%$, respectivamente. No quarto e quinto dia, após a aplicação dos extratos, observaram-se mortalidade larval acumulada de 82 e 88,68 e $80,94,6$ e 96,7 e $100 \%$, nas concentrações 2000; 4000; 6000 e $8000 \mathrm{mg} \mathrm{L}^{-1}$, respectivamente, havendo diferença significativa apenas entre a concentração $4000 \mathrm{mg} \mathrm{L}^{-1}$ em relação a $6000 \mathrm{e}$ $8000 \mathrm{mg} \mathrm{L}^{-1}$ (TABELA 1).

Um dos fatores que afeta a eficiência de um extrato é o solvente extrator. Desta forma, os elevados valores da mortalidade poderão estar associados a forma de extração com o metanol, pois por apresentar uma alta polaridade, pode tornar o extrato mais ativo, portanto, isso pode variar a partir da estrutura vegetal e da espécie do inseto. Por exemplo, Mohapatra et al. (1995) encontraram resultados semelhantes quanto a toxicidade de extratos orgânicos da amêndoa da semente de nim, extraídos pelo aparelho de soxhlet, em cinco diferentes solventes extratores (água, metanol, etanol, acetona e hexano), contra Spodoptera litura e concluíram que o extrato metanólico apresentou o máximo de proteção de folhas, com um percentual de 100; 90,32; 47,31 e 7,50\% de mortalidade, comparado com 93,01; 75,26; 27,96 e 4,30\%, do solvente extrator água, nas concentrações de 1,0; 0,5; 0,1 e $0,01 \%$, respectivamente, havendo diferença estatística apenas nas concentrações 1,0 e $0,5 \%$. Roel (1998) estudou o efeito de diferentes concentrações dos extratos orgânicos (acetônico e metanólico) de ramos e folhas de T. pallida na mortalidade larval de Spodoptera frugiperda e constatou que, no que se refere aos ramos, os dois extratos foram igualmente ativos, enquanto que em relação às folhas, o extrato acetônico apresentou maior atividade que o metanólico.

Segundo Schmutterer (1988) e Mordue \& Blackwell (1993) a morte dos insetos alvo é dependente da dose e do tempo de exposição ao princípio ativo do produto, a qual pode ocorrer em poucos dias da aplicação, podendo este postulado ser aplicado a este estudo, onde a concentração de $8000 \mathrm{mg} \mathrm{L}^{-1}$, passou apenas quatro dias para matar $100 \%$ das lagartas, enquanto nos demais tratamentos, foram necessários mais dois dias de exposição do produto para atingir esta mortalidade. Em casos extremos, as larvas podem viver por muitas semanas, sendo incapazes de realizar ecdise. Verkerk \& Wright (1993) verificaram que extratos aquosos da amêndoa da semente de nim, extraídos com uma mistura de éter e metanol, sobre lagartas de $P$. xylostella, apresentaram uma relação direta entre a concentração e o tempo de exposição do produto, pois na concentração $10 \mu \mathrm{g}$ a.i. $\mathrm{mL}^{-1} \mathrm{o}$ extrato precisou de 11 dias para matar $100 \%$, enquanto a 0,1 e $1,0 \mu \mathrm{g}$ a.i. $\mathrm{mL}^{-1} \mathrm{com} 13$ dias, a mortalidade foi de 52 e $78 \%$, respectivamente, com avaliações realizadas de 5 a 13 dias. Um estudo feito com o inseticida comercial de nim Margosan -O, em laboratório, causou mortalidade de 8, 20, 32, 56 e 100\%, no primeiro ínstar de lagartas de Archips rosanus, nas concentrações de 0,$001 ; 0,01 ; 0,1$ e $1,0 \%$, respectivamente, com $48 \mathrm{~h}$ de exposição do produto (Aliniazee et al., 1997).
Outra hipótese é que a lagarta da traça-do-tomateiro, por apresentar o hábito minador, está exposta ao extrato, de forma mais direta, após a eclosão ou posteriormente, ao passar de uma folha ou de uma mina para outra, quando se alimenta diretamente do tecido vegetal contaminado. Extratos da semente de nim aplicados nas folhas foram eficazes contra uma série de pragas minadoras de folhas em hortaliças como Liriomyza sativae e L. trifolii (Webb et al., 1983). Quando no interior das minas, a traça-do-tomateiro fica sujeita aos compostos ativos que penetrem no tecido vegetal, pois o nim pode apresentar atividade sistêmica, como pode ser comprovado através do trabalho de Gill \& Lewis (1971), utilizando extrato de nim, aplicados ao solo, em cultivo de feijoeiro, contra Schistocerca sp.. Larew et al. (1985) observaram que o extrato etanólico a $0,4 \%$ de sementes de nim, quando aplicado ao solo, afetou L. trifolii em crisântemo, aumentando a mortalidade de larvas nos últimos ínstares.

No presente trabalho, algumas lagartas saíram da mina e não conseguiram mais se alimentar, outras permaneceram no seu interior sem se alimentar, até a morte. Muitas lagartas que saíram da mina apresentaramse "moribundas" com sintomas de paralisia no corpo, sem coordenação motora, com a parte posterior do abdome recurvada e de coloração escura. Essas alterações morfológicas e fisiológicas sugerem, por sua vez, interferência de algum componente do extrato no sistema hormonal que rege o desenvolvimento larval. Mordue \& Blackwell (1993) observaram sintomas semelhantes em relação à não liberação da exúvia, em lagartas submetidas a diferentes doses de azadiractina e atribuíram essas alterações à redução na concentração do ecdisônio ou atraso na sua liberação na hemolinfa. Esses resultados são de grande importância, pois quando se afeta 0 desenvolvimento larval, ou seja, quando se interrompe a biologia nessa fase, obtém-se a diminuição da população do inseto na fase em que ocorre o dano às plantas, desta forma, quando a viabilidade larval é nula, ou melhor, quando ocorre mortalidade total nessa fase, é porque o extrato apresentou uma ótima toxicidade (Tanzubil \& McCaffery, 1990).

Com base nos valores da elevada mortalidade de lagartas, o solvente metanol apresentou ótima eficiência na extração dos compostos ativos de nim, como também mostrou-se em boas condições para extrair ou diluir os extratos, pois não interferiu na eficácia dos mesmos nas concentrações testadas.

Como o extrato estudado foi tóxico para alimentação das lagartas, pode-se deduzir que os produtos derivados de nim podem ser adequados e de grande interesse para o controle da traça-do-tomateiro. Além disso, segundo Schmutterer (1990), apresentam considerável seletividade para inimigos naturais de pragas, especialmente parasitóides e predadores, como também podem ser misturados com outros bioprodutos, como inseticidas à base de Bacillus thuringiensis ou como sinergistas para aumentar sua eficácia. 


\section{CONCLUSÕES}

- Extratos metanólicos da amêndoa da semente de nim causam elevada mortalidade em lagartas da traçado-tomateiro.

- O extrato da amêndoa da semente de nim não afeta a viabilidade de ovos e o período de incubação da traça-do-tomateiro.

- O solvente metanol apresenta ótima eficiência tanto para extrair como para diluir os extratos da amêndoa da semente de nim.

\section{AGRADECIMENTOS}

À Coordenação de Aperfeiçoamento de Pessoal de Nível Superior (CAPES) pela concessão da bolsa de estudo de Mestrado concedida ao primeiro autor e ao Prof. Dr. Edmilson Jacinto Marques pelas sugestões e colaborações.

\section{REFERÊNCIAS BIBLIOGRÁFICAS}

AHMED, S.; GRAINGE, M. Potential of the neem tree (Azadirachta indica) for pest control and rural development. Economic Botany, v.40, p.201-209, 1986.

ALINIAZEE, M.T.; ALHUMEYRI, A.; SAEED, M. Laboratory and field evaluation of a neem insecticide against Archips rosanus L. (Lepidoptera: Tortricidae). The Canadian Entomologist, v.129, p.27-33, 1997.

BEAMENT, J.W.L.; LAL, R. Penetration through the eggshell of Pieris brassicae (L.). Bulletim Entomological Research, v.48, p.109-125, 1957.

BOFF, M.I.C.; ALMEIDA, A.A. Ação tóxica de pimenta-do-reino, Piper nigrum, em ovos de Sitrotoga cerealella (Oliv.) (Lepidoptera: Gelechiidae). Anais da Sociedade Entomológica do Brasil, v.25, p.423-429, 1996.

COELHO, M.C.F.; FRANÇA, F.H. Biologia, quetotaxia da larva e descrição da pupa e adulto da traça-do-tomateiro. Pesquisa Agropecuária Brasileira, v.22, p.129-135, 1987.

COUDRIET, D.L.; PRABHAKER, N.; MEYERDIRK, D.E. Sweetpotato whitefly (Homoptera: Aleyrodidae): effects of neem-seed extract on oviposition and immature stages. Environmental Entomology, v.14, p.776-779, 1985.

CREDLAND, P.F. The structure of bruchid eggs may explain the ovicidal effect of oils. Journal of Stored Products Research, v.28, p.1-9, 1992.

FERRACINI, V.L.; WATANABE, M.A.; FRIGHETO, R.T.S.; SILOTO, R.C. Efeito repelente de extratos vegetais sobre a traça-do-tomateiro (Scrobipalpuloides absoluta, Lepidoptera, Gelechiidae). In: WORKSHOP SOBRE PRODUTOS NATURAIS NO CONTROLE DE PRAGAS, DOENÇAS E PLANTAS DANINHAS, Jaguariúna, 1990. Anais. Jaguariúna: EMBRAPA, CNPDA, 1990. p.49.

FERRACINI, V.L.; WATANABE, M.A.; SILOTO, R.C. Controle da traça-do-tomateiro Scrobipalpuloides absoluta (Lepidoptera: Gelechiidae). In: CONGRESSO BRASILEIRO DE ENTOMOLOGIA, 14., 1993. Piracicaba. Resumos. Piracicaba: SEB, 1993. p.252.

FRANÇA, F.H.; CASTELO BRANCO, M. Ocorrência da traça do tomateiro (Scrobipalpuloides absoluta) em solanáceas silvestres no Brasil Central. Horticultura Brasileira, v.10, p.6-10, 1992.

GILL, J.S.; LEWIS, C.T. Systemic action of na insect feeding deterrent. Nature, v.232, p.402-403, 1971.
GUEDES, R.N.C.; PICANÇO, M.C.; GUEDES, N.M.P.; MADEIRA, N.R. Sinergismo do óleo mineral sobre a toxicidade de inseticidas para Scrobipalpuloides absoluta (Lepidoptera: Gelechiidae). Pesquisa Agropecuária Brasileira, v.30, p.313-318, 1995.

HAJI, F.N.P. Nova praga do tomateiro no Vale do Salitre no Estado da Bahia. Petrolina: EMBRAPA, CPATSA, 1982. 2p. (Comunicado Técnico, 10).

HAJI, F.N.P. Aspectos biológicos da traça-do-tomateiro e seu controle. Petrolina: EMBRAPA, CPATSA, 1984. 2p. (Comunicado Técnico, 13).

HAJI, F.N.P.; SOUZA DIAS, R.C.; ANDRADE, M.W. Controle da traça-do-tomateiro. Petrolina: EMBRAPA, CPATSA, 1989. 2p. (Comunicado Técnico, 39).

HAJI, F.N.P.; PARRA, J.R.P.; SILVA, J.P.; BATISTA, J.G.S. Biologia da traça-do-tomateiro sob condições de laboratório. Pesquisa Agropecuária Brasileira, v.23, p.107-110, 1988.

IMENES, S.D.L.; CAMPOS, T.B.; TAKEMATSU, A.P.; MYASATO, A.; SILVA, M.A.D. Controle químico da traça do tomateiro, Scrobipalpula absoluta (Meyrick, 1917) (Lepidoptera: Gelechiidae). Anais da Sociedade Entomológica do Brasil, v.19, p.281-289, 1990.

JACOBSON, M. Botanical Pesticides: past, present and future. In: ARNASON, J.T.; PHILOGENE, B.J.R.; MORAND, P. Inseticides of plant origin. Washington: ACS, 1989. cap.1, p.1-7.

LAREW, H.G.; KNODEL-MONTZ, J.J.; WEBB, R.E.; WARTHEN, J.D. Liriomyza trifolii (Burgues) (Diptera: Agromyzidae) control on Chrysanthemum by neem seed extract applied to soil. Journal of Economic Entomology, v.78, p.80-84, 1985.

MOHAPATRA, S.; SAWARKAR, S.K.; PATNAIK, H.P.; SENAPATI, B. Antifeedant activity of solvent extracts of neem seed kernel against Spodoptera litura F. and their persistency against through encapsulation. Internacional Journal of Pest Management, v.41, p.154-156, 1995.

MORDUE, A.J.; BLACKWELL, A. Azadirachtin: An Update. Journal of Insect Physiology, v.39, p.903-924, 1993.

NEVES, B.P.; NOGUEIRA, J.C.M. Cultivo e utilização do nim indiano (Azadirachta indica A. Juss.). Goiânia: EMBRAPA, CNPAF; APA, 1996. 32p. (Circular Técnica, 28).

PRATISSOLI, D. Bioecologia de Trichogramma pretiosum (Riley, 1879), nas traças Scrobipalpuloide absoluta (Meyrick, 1917) e Phtorimaea opercula (Veller, 1873) em tomateiro. Piracicaba, 1995. 130p. Tese (Doutorado) - Escola Superior de Agricultura "Luiz de Queiroz", Universidade de São Paulo.

ROEL, A.R. Efeito de extratos orgânicos de Trichilia pallida Swartz (Meliaceae) na sobrevivência e desenvolvimento de Spodoptera frugiperda (J.E. Smith, 1797) (Lepidoptera: Noctuidae). Piracicaba, 1998. 115p. Tese (Doutorado) - Escola Superior de Agricultura "Luiz de Queiroz", Universidade de São Paulo.

SAXENA, R.C. Inseticides from Neem. In: ARNASON, J.T.; PHILOGENE, B.J.R.; MORAND, P. (Ed.) Inseticides of plant origin. Washington: ACS, 1989. cap.9, p.110-129.

SCHMUTTERER, H. Insect growth-disrupting and fecundityreducing ingredients from the neem and chynaberry trees. In: MORGAN, E.D.; MANDAVA, N.B. CRC Handbook of natural pesticides: insect growth regulators; Part B. Boca Raton: CRC Press, 1987. v.3, p.119-167.

SCHMUTTERER, H. Potential of azadirachtin-containing pesticides for integrated pest control in developing and industrialized countries. Journal of Insect Physiology, v.34, p.713-719, 1988.

SCHMUTTERER, H. Properties and potencial of natural pesticides from the in tree, Azadirachta indica. Annual Review of Entomology, v.35, p.271-297, 1990.

SMITH, E.H.; SALKELD, E.H. The use and action of ovicides. Annual Review of Entomology, v.11, p.331-368, 1966.

Scientia Agricola, v.57, n.3, p.407-413, jul./set. 2000 
SOUZA, J. C.; REIS, P.R. Controle da traça-do-tomateiro em Minas Gerais. Pesquisa Agropecuária Brasileira, v.21, p.343-354, 1986.

SOUZA, A.P.; VENDRAMIN, J.D. Efeito ovicida de extratos aquosos de meliáceas sobre Bemisia argentifolii Bellows \& Perring em tomateiro. In: CONGRESSO BRASILEIRO DE ENTOMOLOGIA, 17., Rio de Janeiro, 1998. Resumos. Rio de Janeiro: 1998. p.142.

SOUZA, J.C.; REIS, P.R.; NACIF, A.P.; GOMES, J.M.; SALGADO, L.O. Traça-do-tomateiro: histórico, reconhecimento, biologia, prejuízos e controle. Belo Horizonte: EPAMIG, 1983. 14p. (Boletim Técnico, 2).

TANZUBIL, P.B.; MCCAFERRY, A.R. Effects of azadirachtin and aqueous neem seed extracts on survival, growth and development of the African armyworm, Spodoptera exempta. Crop Protection, v.9, p.383-386, 1990.

THOMAZINI, A.P.B.W. Efeito de genótipos de Lycopersicon spp. e de extratos aquosos de Trichilia pallida Swartz (Meliaceae) sobre Tuta absoluta (Meyrick, 1917) (Lepidoptera: Gelechiidae). Piracicaba, 1999. 95p. Tese (Doutorado) Escola Superior de Agricultura "Luiz de Queiroz", Universidade de São Paulo.
VERKERK, R.H.J.; WRIGHT, D.J. Biological activity of neem seed kernel extracts and synthetic azadirachtin against larvae of Plutella xylostella L. Pesticide Science, v.37, p.83-91, 1993.

VILLAS BÔAS, G.L.; FRANÇA, F.H. Utilização do parasitóide Trichogramma pretiosum no controle da traça-do-tomateiro em cultivo protegido de tomate. Horticultura Brasileira, v.14, p.223-225, 1996.

WEBB, R.; HINEBAUGH, M.A.; LINDQUIST, R.K.; JACOBSON, $M$. Evaluation of aqueous solution of neem seed extract against Liriomyza sativae and L. trifolii (Diptera: Agromyzidae). Journal of Economic Entomology, v.76, p.357-362, 1983.

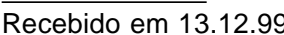

